\title{
CFD MODELING OF STEAM CONDENSATION IN INDUSTRIAL PIPES
}

\author{
N. PADOIN ${ }^{1}$ and C. SOARES ${ }^{1}$ \\ ${ }^{1}$ Federal University of Santa Catarina, Department of Chemical and Food Engineering \\ E-mail contact: cintia.soares@ufsc.br
}

\begin{abstract}
Phase change is a phenomenon frequently encountered in the process industry's equipment. The prediction of its occurrence is important for the optimized design and operation of such operation units. The numerical simulation of vapor condensation in industrial pipes, for instance, allows for the assessment of pumping requirements and best practices for insulation. In this study, a commercial CFD code was applied for the investigation of condensation in pipes. The volume of fluid (VOF) approach was employed for the reconstruction of the vapor-liquid interface and the amount of liquid condensed was evaluated under different operational conditions, i.e., channel dimensions, mass flow rate and heat load from the wall. The results obtained from the CFD simulations were compared with the predictions from classical correlation and showed good agreement.
\end{abstract}

\section{INTRODUCTION}

Condensation occurs when the temperature of a vapor is reduced to a value below its saturation temperature. In particular, three mechanisms are observed: film or droplet condensation, due to vapor contact with a cold surface; homogeneous condensation, associated to fog formation due to pressure reduction; and direct contact condensation, when the vapor comes into contact with a cold liquid (Incropera et al., 2008).

This phase change phenomenon is a problem of theoretical and practical interest, since it occurs in several industrial applications (Marto, 1992; Chen and Lin, 2009). In particular, film-wise condensation inside horizontal tubes has been the subject of many theoretical (Chen and Lin, 2009) and experimental investigations (Marto, 1992; Ge et al., 2013), which spam from pure to mixture vapors (with condensable and non-condensable gases) and a variety of geometrical configurations (e.g., circular and elliptical) and flow orientations. Although some research has been done regarding steam condensation, most of the research published has focused on the analysis of refrigerants, such as R-22 and R-134a.

In condensing flows, parameters related to the heat transfer phenomenon, such as the heat transfer coefficient and its variation during the condensation of the vapor on the wall, and the hydrodynamics, such as the flow pattern developed within the equipment as liquid is formed, have a considerable effect on the performance of the overall processes. The flow pattern, in particular, can 


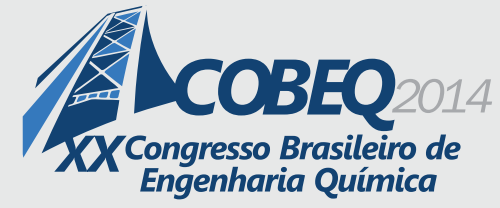

range from the stratified pattern to the annular one, each of which featuring different characteristics of pressure loss and wall friction, for instance. All these physics can be predicted through controlvolume based models (Lee et al., 2013).

In this study, a theoretical investigation of film-wise condensation of saturated steam in a circular horizontal tube based on the model of Lee (1979) was proposed. Different scenarios, in which the effect of operational variables such as the heat load at the walls, the flow rate and the channel diameter, were studied through numerical simulation with the commercial code ANSYS $^{\circledR}$ CFD (Fluent $^{\circledR}$ ) version 15.0. Furthermore, the numerical results were compared with the classical correlation developed by Sarma et al. (1972).

\section{MODEL}

The Volume of Fluid (VOF) method was adopted for the solution of the vapor-liquid flow with phase change in the horizontal channel section taken into account for the analysis. In this context, a single momentum equation was solved and the velocity field was shared by the liquid and the vapor phases. The time-dependent Navier-Stokes equations, considering Newtonian fluids, assume the form presented in Equation 1 (ANSYS, 2013):

$$
\frac{\partial}{\partial t}(\rho \mathbf{v})+\nabla \cdot(\rho \mathbf{v v})=-\nabla p+\nabla \cdot\left[\mu\left(\nabla \mathbf{v}+\nabla \mathbf{v}^{T}-\frac{2}{3} \mu \nabla \cdot \mathbf{v} I\right)\right]+\rho \mathbf{g}+\mathbf{F},
$$

where $t(\mathrm{~s})$ is time, $\rho\left(\mathrm{kg} \cdot \mathrm{m}^{-3}\right)$ is the density, $v\left(\mathrm{~m} \cdot \mathrm{s}^{-1}\right)$ is the velocity vector, $p(\mathrm{~Pa})$ is the pressure, $\mu\left(\mathrm{kg} \cdot \mathrm{m}^{-1} \cdot \mathrm{s}^{-1}\right)$ is the dynamic viscosity, $\boldsymbol{g}\left(\mathrm{m} \cdot \mathrm{s}^{-2}\right)$ is the gravity acceleration and $\boldsymbol{F}\left(\mathrm{kg} \cdot \mathrm{m}^{-2} \cdot \mathrm{s}^{-2}\right)$ represents external forces.

The effect of the surface tension at the vapor-liquid interface was taken into account by the specification of the volumetric source term $\boldsymbol{F}$ in Equation 1, according to Equation 2 (ANSYS, 2013):

$$
\mathbf{F}=\sigma_{l v} \frac{\alpha_{l} \rho_{l} \kappa_{v} \nabla \alpha_{v}+\alpha_{v} \rho_{v} \kappa_{l} \nabla \alpha_{l}}{1 / 2\left(\rho_{l}+\rho_{v}\right)}
$$

where $\sigma_{l v}\left(\mathrm{~kg} \cdot \mathrm{s}^{-2}\right)$ is the surface tension acting on the vapor-liquid interface, $\alpha_{l}$ and $\alpha_{v}$ are the volume fractions of the liquid and vapor phases, respectively, and $\kappa_{l}$ and $\kappa_{v}$ (dimensionless) are the curvature of the interface regarding the vapor and liquid phases, where $\kappa_{l}=\Delta \alpha_{l} /\left|\nabla \alpha_{l}\right|$ and $\kappa_{v}=\Delta \alpha_{v} /\left|\nabla \alpha_{v}\right|$.

The energy conservation through the computational domain, shared by the vapor and the liquid phases, was solved by Equation 3 (ANSYS, 2013):

$$
\frac{\partial}{\partial t}(\rho E)+\nabla \cdot[\mathbf{v}(\rho E+p)]=\nabla \cdot(k \nabla T)+Q
$$

where $E\left(\mathrm{~J} \cdot \mathrm{m}^{-3}\right)$ is the energy, $k\left(\mathrm{~W} \cdot \mathrm{m}^{-1} \cdot \mathrm{K}^{-1}\right)$ is the effective heat conduction coefficient, $T(\mathrm{~K})$ is the 
temperature and $Q\left(\mathrm{~J} \cdot \mathrm{m}^{-3}\right)$ is a heat source term.

All the physical properties of the fluids were calculated through a volume-weighted procedure, according to Equation 4:

$$
\phi=\alpha_{l} \phi_{l}+\alpha_{v} \phi_{v}
$$

where $\phi$ is a generic property $(\rho, k$ or $\mu)$ and the subscripts $l$ and $v$ refer to the liquid and the vapor phases, respectively. Moreover, the energy of the mixture, $E$, is calculated according to Equation 5 (YANG et al., 2008):

$$
E=\frac{\alpha_{l} \rho_{l} E_{l}+\alpha_{v} \rho_{v} E_{v}}{\alpha_{l} \rho_{l}+\alpha_{v} \rho_{v}}
$$

where $E_{\mathrm{l}}=C_{\mathrm{v}, \mathrm{l}}(T-298.15)$ and $E_{\mathrm{v}}=C_{\mathrm{v}, \mathrm{v}}(T-298.15)$.

The tracking of the interface between the vapor and liquid phases was accomplished by the solution of the volume fraction conservation equation, represented by Equation 6 (YANG et al., 2008):

$$
\frac{\partial \alpha_{l}}{\partial t}+\nabla \cdot\left(\mathbf{v} \alpha_{l}\right)=\frac{S}{\rho_{l}} .
$$

The mass transfer rate $S$ from the vapor to the liquid phase due to condensation in the channel was computed by mechanistic model developed by Lee (1979), expressed according to Equation 8 (ANSYS, 2013):

$$
S=\left\{\begin{array}{l}
c_{1} \alpha_{l} \rho_{l} \frac{\left(T_{l}-T_{s a t}\right)}{T_{s a t}}, T_{l}>T_{s a t} \\
c_{2} \alpha_{v} \rho_{v} \frac{\left(T_{s a t}-T_{v}\right)}{T_{s a t}}, T_{v}<T_{s a t}
\end{array},\right.
$$

where $T_{\text {sat }}$ is the saturation temperature of the fluid. The coefficients $c_{1}$ and $c_{2}\left(\mathrm{~s}^{-1}\right)$ should be tuned to each case in particular, through fitting of the model to experimental data, if available. However, if the interface temperature is assumed as the saturation temperature, i.e., no resistance to heat transfer is taken into account, the value of $c$ can be assumed as $100 \mathrm{~s}^{-1}$. This procedure ensure that $T_{i}=T_{\text {sat }}$ with an error of $\pm 1 \mathrm{~K}$ (YANG et al., 2008).

\section{METHOD}

All the simulations were carried out with the commercial code ANSYS ${ }^{\circledR}$ CFD (Fluent $^{\circledR}$ ), version 15.0. The computational domain consisted of a 3D horizontal channel with diameters of 


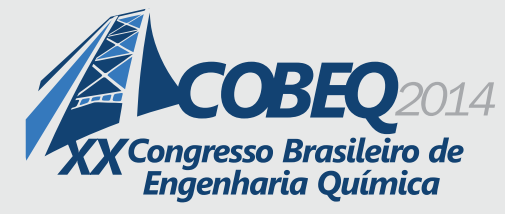

$0.04 \mathrm{~m}$ and $0.05 \mathrm{~m}$ and length of $2 \mathrm{~m}$. At the inlet a velocity of saturated water vapor (quality = $100 \%$ ) was imposed in the range of 4 to $5 \mathrm{~m} \cdot \mathrm{s}^{-1}$, while constant pressure $\left(p=p_{\text {atm }}\right)$ was set at the outlet. Furthermore, constant temperatures of $293.15 \mathrm{~K}$ and $343.15 \mathrm{~K}$ were imposed at the wall. Figure 1 shows a 2D scheme of the computational domain with its main features.

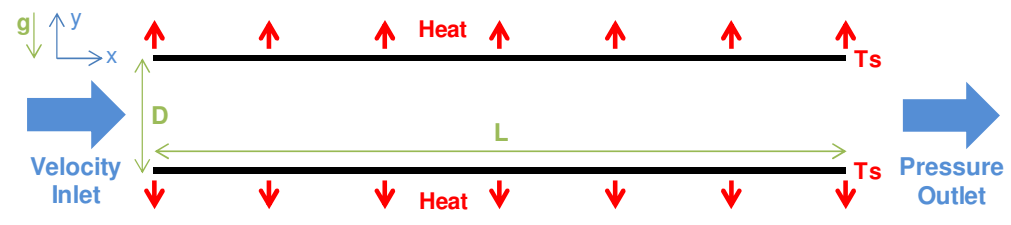

Figure $1-2 \mathrm{D}$ scheme of the computational domain and the boundary conditions adopted. The $\mathrm{z}$-coordinates are out of the plane.

The properties of the vapor and the liquid phases are summarized in Table 1. The vapor phase was assumed as an ideal gas to allow for the computation of variations in the density due to temperature gradients.

Table 1 - Properties of the fluids used in the simulations

\begin{tabular}{cccccc}
\hline Phase & $\rho\left(\mathrm{kg} \cdot \mathrm{m}^{-3}\right)$ & $\mathrm{Cp}\left(\mathrm{J} \cdot \mathrm{kg}^{-1} \cdot \mathrm{K}^{-1}\right)$ & $\mathrm{k}\left(\mathrm{W} \cdot \mathrm{m}^{-1} \cdot \mathrm{K}^{-1}\right)$ & $\mu\left(\mathrm{kg} \cdot \mathrm{m}^{-1} \cdot \mathrm{s}^{-1}\right)$ & $\Delta \mathrm{H}^{0}\left(\mathrm{~J} \cdot \mathrm{kmol}^{-1}\right)$ \\
\hline Vapor & Ideal Gas & 2080 & 0.025095 & $1.2269 \times 10^{-5}$ & $4.068 \times 10^{7 *}$ \\
Liquid & 958.35 & 4216 & 0.67909 & 0.00028174 & 0 \\
\hline
\end{tabular}

*Reference temperature of $373.15 \mathrm{~K}$.

Steady-state simulations were carried out with an VOF implicit scheme. The pressure-velocity coupling was solved though the SIMPLE method. Moreover, the discretization of the spatial gradients was carried out with the Least Squares Cell Based scheme, the PRESTO! method was used for the pressure discretization, the time discretization was performed with the First Order Upwind scheme and all other variables were treated through the Second Order Upwind method. Furthermore, the effects of turbulence were taken into account through the SST-k $\omega$ model.

The mesh consisted of hexahedral elements with a boundary layer of five elements near the wall. A mesh refinement study was carried out in order to evaluate the independence of the results obtained regarding the numerical grid. For this analysis, the average velocity at a plane located $1.5 \mathrm{~m}$ from the inlet was chosen as the critical parameter, since it is an intensive property (i.e., does not take into account any characteristic length in its computation). In particular this study was carried out for the channel with diameter of $0.04 \mathrm{~m}$ and $0.05 \mathrm{~m}$, wall temperature of $343.15 \mathrm{~K}$ and vapor inlet velocity of $5 \mathrm{~m} \cdot \mathrm{s}^{-1}$. It was found that the solution was approximately constant for a mesh consisted of about $9 \cdot 10^{5}$ elements.

In order to evaluate the quality of the results obtained with the CFD simulations, the average numerical heat transfer coefficient was compared with the predictions obtained from the empirical 


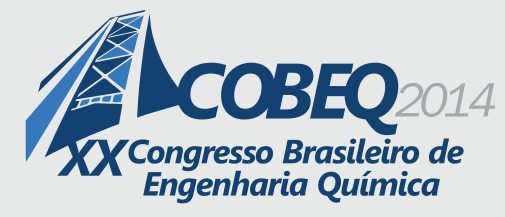

correlation developed by Sarma et al. (1972) (apud Halouani et al., 1997), valid for low vapor flow rates, presented in Equation 10:

$$
\bar{h}=10.65 \frac{k_{l}}{D} \frac{\operatorname{Pr}^{0.25} \mathrm{Ku}^{-1.25}}{\operatorname{Ar}^{0.2}(L / D)^{1.35}}\left(\frac{\rho_{l}-\rho_{v}}{\rho_{l}}\right)^{0.45}\left(\frac{4 q L}{h_{f g} \mu_{l}}\right)^{1.2},
$$

where $D(\mathrm{~m})$ is the channel inner diameter, $\operatorname{Pr}$ is the dimensionless Prandtl number $(\operatorname{Pr}=C P \mu / k), K u$ is the dimensionless Kutateladze number $\left[K u=C p\left(T_{s a t}-T_{s}\right) / h_{f g}\right], A r$ is the dimensionless Archimedes number $\left[A r=D^{3} g \rho_{l}^{2}\left(\rho_{l}-\rho_{v}\right) / \rho_{l} \mu_{l}^{2}\right], L(\mathrm{~m})$ is the channel length, $q\left(\mathrm{~W} \cdot \mathrm{m}^{-2}\right)$ is the heat flux from the wall and $h_{f g}\left(\mathrm{~J} \cdot \mathrm{kg}^{-1}\right)$ is the latent heat of vaporization. It should be noted that, in the conditions were Equation 10 should be applied, the liquid phase develops a stratified flow pattern (similar to the scenario evaluated in this study).

\section{RESULTS AND DISCUSSION}

Figure 2 presents isosurfaces of liquid volume fraction at four locations along the computational domain, for $D=0.05 \mathrm{~m}, v_{i n}=5 \mathrm{~m} \cdot \mathrm{s}^{-1}$ and $T_{s}=343.15 \mathrm{~K}$, and a 3D view of the domain showing the liquid phase stratified flow pattern (considering a cut-off $\alpha_{l}=4.5 \times 10^{-4}$ ).
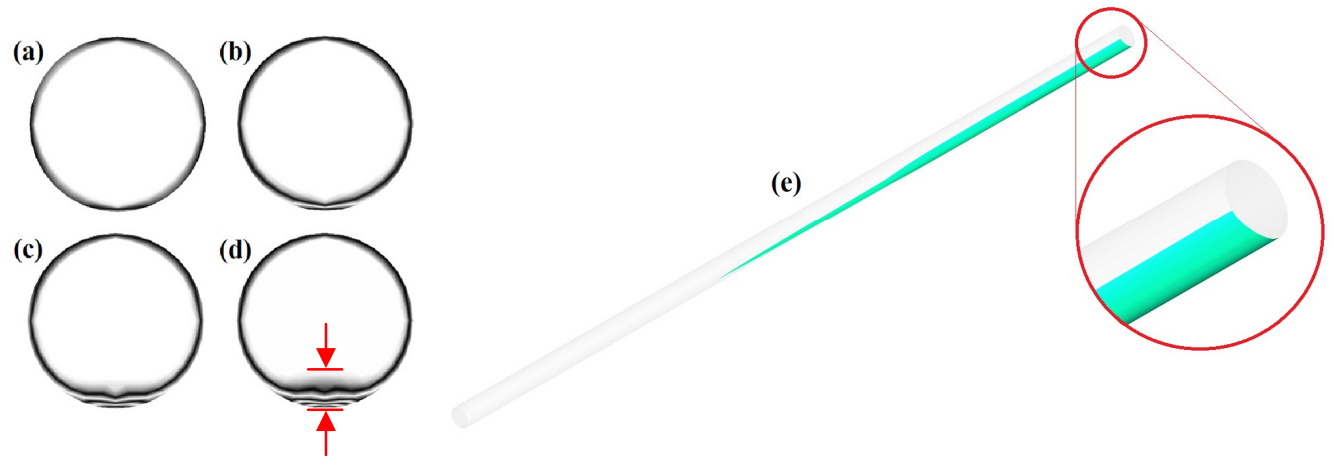

Figure 2 - Contours of liquid volume fraction: at the cross-section of the channel at (a) $0.5 \mathrm{~m}$,

(b) $1.0 \mathrm{~m}$, (c) $1.5 \mathrm{~m}$ and (d) $2.0 \mathrm{~m}$ from the inlet and (e) a 3D view of the domain.

It is possible to observe that the CFD simulations captured the thin liquid film formed along the entire inner surface of the channel as well as the thicker film at the bottom of the tube due to the effect of gravity on the flow, leading to a stratified pattern with the increase of the axial coordinates. This effect is characteristic of the operational range investigated, especially regarding the low flow rate adopted (Incropera et al., 2008). Therefore, the model developed by Lee (1979) and implemented in the commercial code ANSYS ${ }^{\circledR}$ CFD (Fluent $^{\circledR}$ ) version 15.0 can describe with considerable reliability, at least qualitatively, the condensation phenomenon in industrial pipes, allowing for the prediction of the flow pattern developed as the vapor condenses. It is interesting to note that the simple visualization of the flow pattern can be a good indicative of the performance of an equipment 


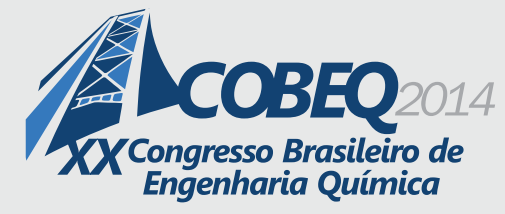

19 a 22 de outubro de 2014

Florianópolis/SC

under the operational conditions of interest, yielding an assessment of pressure drop and regions of potential enhanced corrosion at the wall, for instance. Since water has a high calorific capacity, the main flow patterns observed as its vapor condenses in horizontal pipes are the stratified and annular, achieved as the inlet velocity increases (Incropera et al., 2008). However, fluids with considerably lower calorific capacity exhibit a variety of flow patterns as liquid is formed by condensation and it is even possible that the entire cross-section of the channel could be filled with liquid, which becomes the continuous phase, and the vapor flows in the form of bubbles or slugs. The CFD code can predict all these scenarios through the modeling of interfacial mass transfer based on Lee's (1979) model. Finally, it should be pointed out that values of channel length and diameter used in this study were selected to allow the visualization of the flow pattern with a manageable computer cost.

Figure 3 shows the variation of the mean vapor quality throughout the channel as a function of the scenarios investigated. For the channel with diameter of $0.05 \mathrm{~m}$ the vapor quality showed a linear decay profile along with the dimensionless axial coordinates. It is interesting to note that decreasing the inlet vapor velocity from $5 \mathrm{~m} \cdot \mathrm{s}^{-1}$ to $4 \mathrm{~m} \cdot \mathrm{s}^{-1}$ did not change the behavior of such profile, but has an effect on his slope. In particular, a higher decay of vapor quality, i.e., more liquid condensation, was observed as the vapor moved slower along the domain.

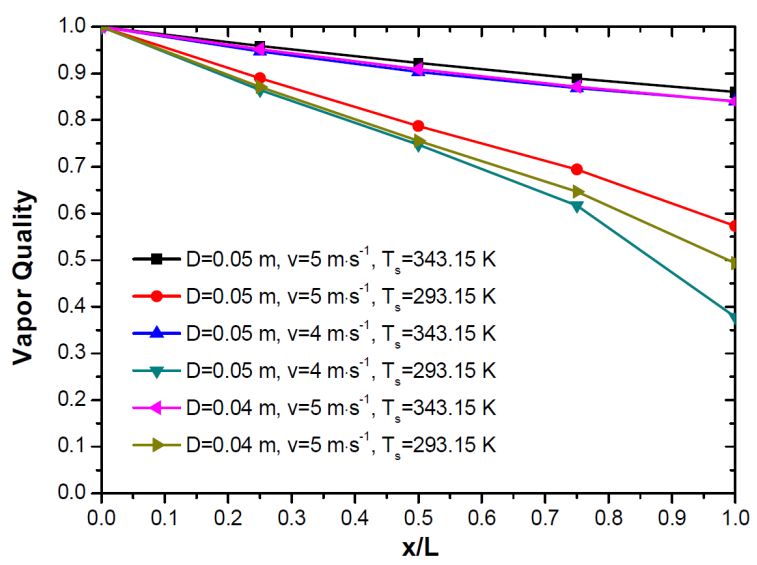

Figure 3 - Vapor quality as a function of the axial dimensionless coordinates of the channel.

However, when the temperature of the wall was decreased from $343.15 \mathrm{~K}$ to $293.15 \mathrm{~K}$, the profile of variation of vapor quality along the dimensionless axial coordinates of the channel changed to an exponential decay shape, indicating a higher rate of condensation at the exit of the tube. Moreover, for the wall temperature of $293.15 \mathrm{~K}$ the decrease of inlet vapor velocity from $5 \mathrm{~m} \cdot \mathrm{s}^{-1}$ to $4 \mathrm{~m} \cdot \mathrm{s}^{-1}$ leaded to a more pronounced variation in the rate of condensation along the channel length, with a higher decrease of the vapor quality with the lower inlet velocity.

Furthermore, it was observed that decreasing the tube diameter from $0.05 \mathrm{~m}$ to $0.04 \mathrm{~m}$ did not have a significant effect on the variation of vapor quality along the axial coordinates of the channel. Considering an inlet vapor velocity of $5 \mathrm{~m} \cdot \mathrm{s}^{-1}$, there was a decrease of the vapor quality from $100 \%$ 


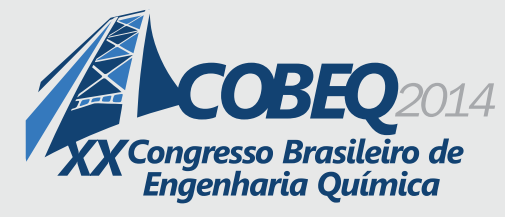

to approximately $85 \%$ for the wall temperature of $343.15 \mathrm{~K}$ and from $100 \%$ to approximately $49 \%$ for the wall temperature of $293.15 \mathrm{~K}$. Again, it was observed a linear rate of condensation for the wall temperature of $343.15 \mathrm{~K}$ and an exponential decrease for the wall temperature of $293.15 \mathrm{~K}$.

The numerical results were compared to the predictions of the empirical correlation developed by Sarma et al. (1972) (apud Halouani et al., 1997) and presented in Equation 10. The value of the average heat transfer coefficient predicted by the CFD code was in acceptable agreement with the value predicted from the empirical correlation, considering the precision of the model developed by Lee (1979) and implemented in the commercial code ANSYS ${ }^{\circledR}$ CFD (Fluent ${ }^{\circledR}$ ). For example, for the case of a pipe with internal diameter of $0.04 \mathrm{~m}$, inlet vapor velocity of $5 \mathrm{~m} \cdot \mathrm{s}^{-1}$ and wall temperature of $343.15 \mathrm{~K}$, the predicted average value of $\bar{h}$ from the correlation was $24.74 \mathrm{~W} \cdot \mathrm{m}^{-2} \cdot \mathrm{K}^{-1}$, while the value obtained from the CFD simulation was $97.12 \mathrm{~W} \cdot \mathrm{m}^{-2} \cdot \mathrm{K}^{-1}$. It should be noted that, although the relative difference of these values is apparently high, they are in the same order of magnitude.

It should be mentioned that the correlations available in the literature for the assessment of the phenomenon of condensation in circular horizontal tubes are mainly concerned with the prediction of the heat transfer coefficient. However, they are quite incomplete, since some of them take into account important flow parameters, such as the velocity at the, but do not consider thermal effects due to the temperature difference between the wall and the fluid. On the other hand, other proposed correlations account for the thermal effect but do not take into account flow parameters or even neglect geometrical features such as the channel length. Therefore, the correlation developed by Sarma et al. (1972) (apud Halouani et al., 1997) should be considered as an indicative parameter, not as a robust reference, since this empirical model, in particular, do not accounts for flow properties (mainly the velocity).

Moreover, the model developed by Lee (1979) and implemented in the commercial CFD code used in this study presents a relevant limitation due to the adjustable evaporation-condensation factor $c$. In fact, the computational model could be enhanced through the tuning of this parameter. It should be noted, however, that decreasing such factor causes a higher difference of the temperature of the interface regarding the vapor saturation temperature, which could, in fact, decrease the accuracy of the model, while higher values of $c$ can lead to convergence problems. Thus, the better strategy for simulations of condensation through Lee's model in the context of the CFD code evaluated is, indeed, to optimize the value of the constant $c$ by successive comparisons between the numerical predictions and experimental data collected in the same range of operation and similar geometric features.

\section{CONCLUSIONS}

CFD can predict film-wise condensation of saturated vapors inside horizontal circular pipes with an acceptable precision. In particular, the model developed by Lee (1979) and implemented in the commercial code ANSYS ${ }^{\circledR}$ CFD $\left(\right.$ Fluent $^{\circledR}$ ), version 15.0, can be applied in the context of the Volume of Fluid (VOF) method, allowing for the simulation of a wide range of flow configurations and patterns.

In particular, the CFD simulations predicted the development of a stratified flow pattern as the 


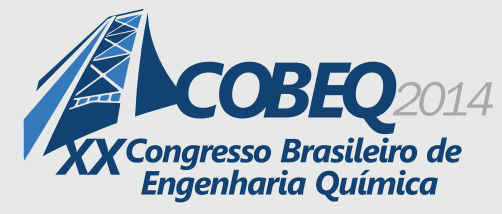

vapor condensed to liquid due to contact with the cold wall of the channel. It was observed that there was a linear variation of the vapor quality from the inlet of the pipe along the dimensionless axial coordinates when the wall temperature was $343.15 \mathrm{~K}$, for the inlet vapor velocity of 4 to $5 \mathrm{~m} \cdot \mathrm{s}^{-1}$ and for both internal diameters of $0.04 \mathrm{~m}$ and $0.05 \mathrm{~m}$, while there was an pseudo-exponential decay of the vapor quality along the length of the channel for the wall temperature of $293.15 \mathrm{~K}$.

The value of the average heat transfer coefficient predicted by the CFD code was in the same order of magnitude than the corresponding parameter calculated by the empirical correlation developed by Sarma et al. (1972) (apud Halouani et al., 1997). Further improvements in the CFD model, especially regarding the evaporation-condensation factor $c$ of the Lee's model, could lead to even better predictions.

\section{ACKNOWLEDGEMENT}

The authors acknowledge CNPq (Conselho Nacional de Desenvolvimento Científico e Tecnológico) for the scholarship (process number 140521/2014-3).

\section{REFERENCES}

ANSYS Fluent. Theory guide v15.0, Canonsburg, PA, USA, 2013.

CHEN, C.-K.; LIN, Y.-T. Laminar film condensation from a downward-flowing steam-air mixture onto a horizontal circular tube. Appl. Math. Model., v. 33, p. 1944-1956, 2009.

GE, M.; ZHAO, J.; WANG, S. Experimental investigation of steam condensation with high concentration of $\mathrm{CO}_{2}$ on a horizontal tube. Appl. Therm. Eng., v. 61, p. 334-343, 2013.

HALOUANI, K.; AYADI, A.; EL HALOUANI, F.; FEIDT, M. Étude hydrodynamique et thermique de la condensation en film à l'intérieur d'un tube horizontal, Rev. Gén. Therm., v. 36, p. 655665, 1997.

INCROPERA, F. P.; BERGMAN, T. L.; DEWITT, D. P. Fundamentos de transferência de calor e de massa. 6. ed. Rio de Janeiro: LTC, 2008.

LEE, W. H. A pressure iteration scheme for two-phase modeling. Technical Report LA-UR 79-975, Los Alamos Scientific Laboratory, Los Alamos, New Mexico, 1979.

LEE, H.; MUDAWAR, I.; HASAN, M. M. Flow condensation in horizontal tubes. Int. J. Heat Mass Tran, v. 66, p. 31-45, 2013.

MARTO, P. J. Film condensation heat transfer measurements on horizontal tubes: problems and progress. Exp. Therm. Fluid Sci., v. 5, p. 556-569, 1992.

SARMA, A. S. P.; SARMA, P. K.; APPARAW, K. V. An empirical correlation for condensation heat transfer under one component stratified flow conditions, Can. J. Chem. Eng., v. 50, p. 541-543, 1972.

YANG, Z.; PENG, X. F.; YE, P. Numerical and experimental investigation of two-phase flow during boiling in a coiled tube. Int. J. Heat Mass Tran., v. 51, p. 1003-1016, 2008. 